\title{
COMPUTER-ASSISTED MODELING AND DESIGN OF COMPRESSION GARMENTS WITH GRADED UNIT COMPRESSION
}

\author{
Krzysztof Kowalski ${ }^{1}$, Magdalena Kłonowska ${ }^{1}$, Witold Sujka, ${ }^{2, *}$ Ilona Latańska², Tomasz Marek Kowalski ${ }^{3}$ \\ 1 Department of Knitting Technology and Textile Machines, Lodz University of Technology, Lodz, Poland \\ 2 Tricomed SA, Lodz, Poland \\ 3 Department of Computer Engineering, Lodz University of Technology, Lodz, Poland \\ ${ }^{*}$ Corresponding author. E-mail: witold.sujka@tzmo-global.com
}

\begin{abstract}
:
This article presents a useful algorithm for designing compression products with intended and graded unit pressure along the part of the body covered with the mentioned garments. The algorithm was developed using Laplace's law and a designated experimental function describing the relationship between strength and relative elongation of knitted fabric, and the results of 3D scanning of different body parts. On this basis, two examples of products in the form of a leg sleeve and arm sleeve were designed for the treatment of lymphoedema in compression classes II and III. The presented compression product design procedure facilitates the process of designing compression garments and eliminates some errors related to this procedure.
\end{abstract}

\section{Keywords:}

Design algorithm, compression products, unit pressure, Laplace's law, compression classes

\section{Introduction}

Custom-made, personalized products are among the most useful compression garments used in therapies supporting the external healing process. Such products should be designed using Laplace's law [1-4]. Designing products based on a fixed percentage reduction of basic construction dimensions, regardless of the size of the patient's body circumferences, which is often $10 \%$ for the first set of compression garments and $15 \%$ or $20 \%$ for all subsequent products [5-9], usually leads to values of unit pressure that are uncontrolled and noncompliant with the recommendations. Depending on the type of therapy, the unit pressure can have a constant value along the covered part of the body, in the case of burn wounds, postoperative liposuction wounds, and hernias. It can also have a graded value, as in the treatment of lymphoedema and anti-varicose edema. The value of the unit pressure in such cases decreases gradually toward the heart. An important factor in the design procedure is the replacement of manual body part measuring with a 3D scanning technique. Such proceeding shortens the measurement time and eliminates some reasons for the scatter of measurement results associated with the manual method of dimensioning the human body [10-17]. Another important element in the procedure of modeling and designing compression products is the development of a compression knitted fabric assessment method, which should correspond to the assessment of the compression garment in terms of the required pressure value. Therefore, it is important to include the mechanical characteristics of knitted fabric in the form of the relationship of the force $F$ with the relative elongation $\varepsilon$, and various relations between the parameters $F$ and $\varepsilon$ - depending on the extent of stretching [18]. In articles [2, 19, 20], for the purposes of compression garments modeling, a constant value of knitted fabric tensile stiffness is assumed, regardless of the value of relative elongation. However, in the case of designing a product, the real relations between the values of force $F$ and relative elongation $\varepsilon$ should be assumed which, depending on the range of relative elongation of compression knitwear, assume different values, as evidenced by nonlinear relationships $F=f(\varepsilon)[18,21,22]$. The compression garments design procedure should also take into account the relationships between the tensile stiffness of the fabric and the size of the body circumferences and the presence of the seam [19], as well as the impact of the body's local susceptibility to changes in the unit pressure [23]. However, in the case of standardized products, an important factor is the selection of tensile stiffness for a given compression class and size, as well as dimensional tolerance of the size range [24].

The research presented in this work aims to develop an algorithm used for the design of a compression product that will allow for determining the free dimensions of the product with the intended and graded value of the unit pressure along the part of the body covered with the compression garment.

\section{Methodology}

\subsection{Basics of modeling and desian of compression products}

The basic law used in the modeling and design of compression products is Laplace's law. Depending on the type of therapy, the intended value of unit pressure $P_{i}(\mathrm{hPa})$ can be constant or graded as 


$$
P_{i}=\frac{2 \pi \cdot F_{i}}{G_{i} \cdot s} .
$$

The second important equation in the design procedure of compression products describes the mechanical characteristics of the knitted fabric in the form of the relationship of force $\mathrm{F} / \mathrm{cm}$ and relative elongation $\varepsilon[18]$ as

$$
F\left[\frac{\mathrm{cN}}{\mathrm{cm}}\right]=a_{1} \cdot \varepsilon^{3}+b_{1} \cdot \varepsilon^{2}+c_{1} \cdot \varepsilon
$$

where $a_{1}, b_{1}$, and $c_{1}$ are regression coefficients and $\varepsilon$ is the relative elongation of the knitted fabric, which for the modeling purposes is described by the following equation

$$
\varepsilon=\frac{G_{i}}{G_{0 i}}-1
$$

where $G_{0 i}$ is the $i$-th circumference of the compression product in the relaxed state. Using Eqs (1)-(3) and their solutions with respect to $G_{0 i}$, we obtain the required value of $G_{0 i}$ circumferences of the compression product for the declared values of unit pressure $P_{i}$ and $G_{i}(\mathrm{~cm})$ body circumferences (Figure 1).

\subsection{The algorithm of designing compression garments with graded compression}

The algorithm of designing compression garments with graded unit compression along the covered body part, presented in Figure 2, was developed using (1) Laplace's law and

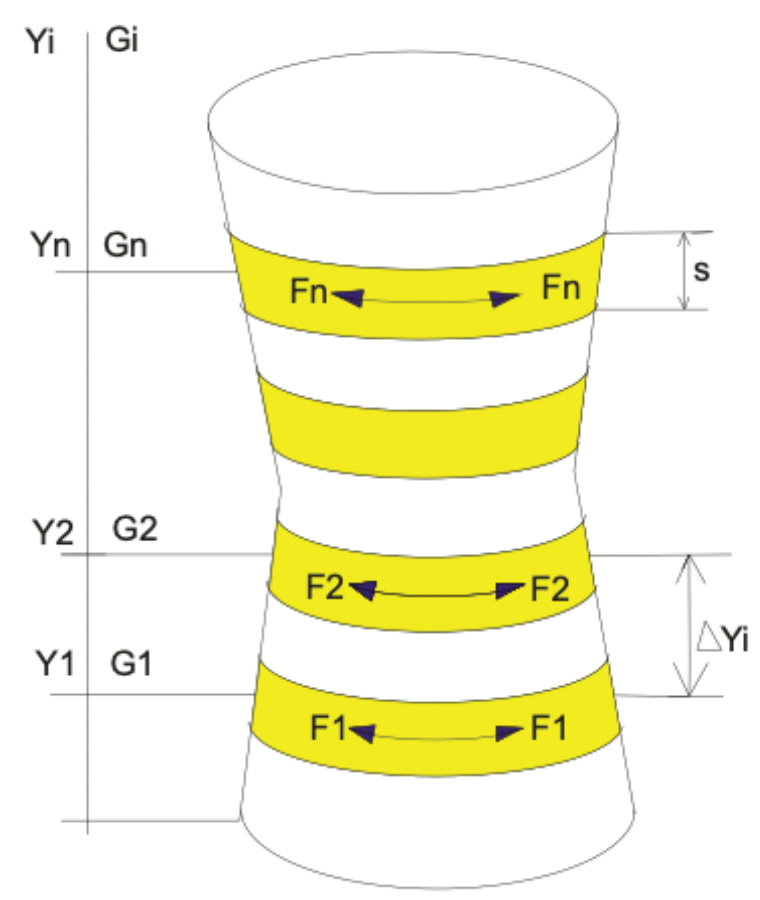

Figure 1. Model of a body part with different values of $G_{i}$ circumferences, where $G_{1}, G_{2}, \ldots, G_{n}$ are the subsequent body part circumferences $Y_{1}, Y_{2}, \ldots, Y_{n}$ are the subsequent distances between the circumferences and the base, $F_{1}, F_{2}, \ldots, F_{n}$ are the circumferential forces in compression fabric strip of width $s$ for subsequent circumferences, and $\Delta Y_{i}$ is the distance between the subsequent circumferences.
(2) the generalized form of the function of the mechanical characteristics of the compression knitted fabric in the form of the relation between force $F$ and the relative elongation $\varepsilon$ [18]. The pressure gradient along the limb of the human body complies with the guidelines of the subject standards [25-27].

In the first part of the algorithm, the form of the function of pressure gradient on the basis of quadratic interpolation is determined as

$$
P_{i}(Y)=A Y_{i}^{2}+B Y_{i}+P_{s r}
$$

The output data of this part of the algorithm based on a model leg (Figure 3 ) are the following parameters:

$P_{s r}$ is the middle value of the unit pressure for a given compression class;

$Y_{G}$ is the maximum distance of the circumference from the base;

$k_{G}$ is the set factor of unit pressure reduction for the circumference at point $G\left(Y_{G}\right)$;

$y_{C}$ is circumference position coefficient $C\left(y_{C}, \ldots, Y_{G}\right)$;

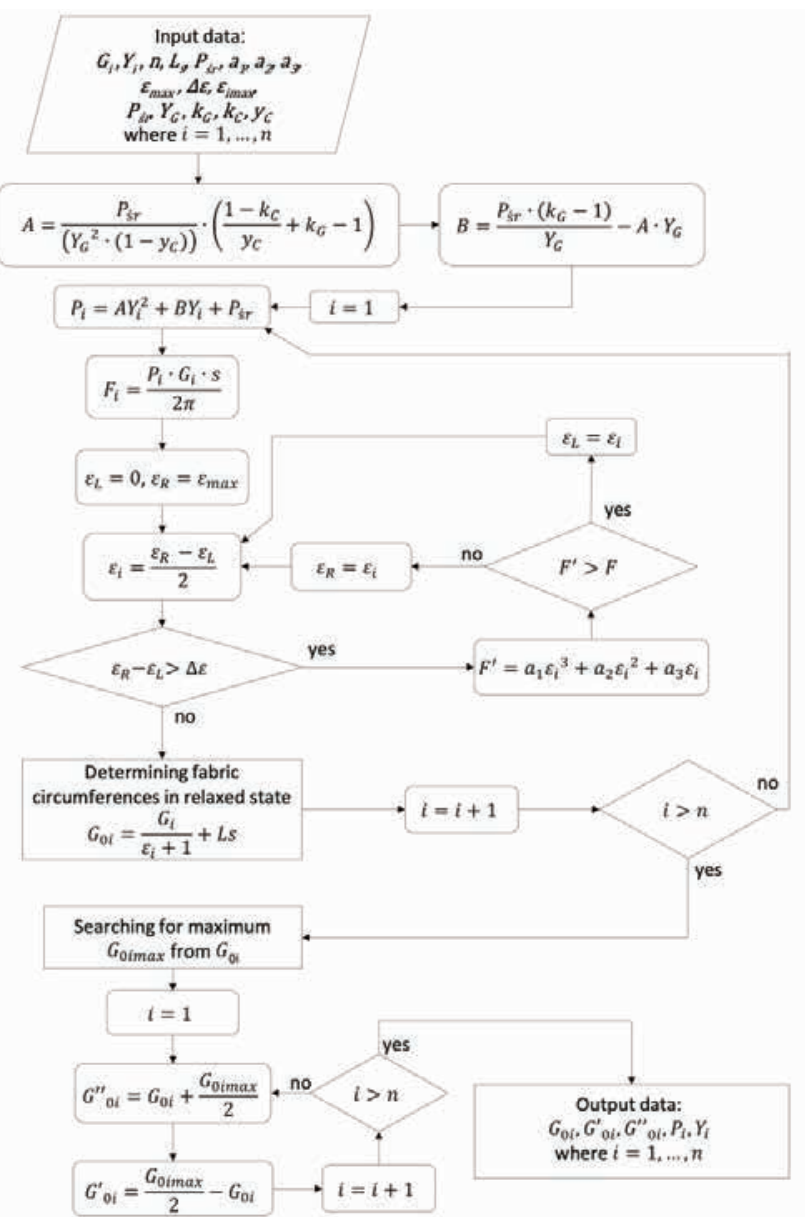

Figure 2. The algorithm for establishing free dimensions of a template for compression garments. 
$k_{C}$ is set unit pressure reduction factor for the circumference at point $C\left(y_{C}, \ldots, Y_{G}\right)$.

The $P_{i}$ unit pressure values are described in the function determined from the range of the maximum and minimum pressure values in accordance with the guidelines of PN-ENV 12718: 2002 Medical compression hosiery. For the purposes of modeling, it was assumed that the pressure value in the ankle area is $100 \%$, which then decreases degressively toward the maximum calf circumference (point $C$ ) to $70 \%$ of the initial value of $P_{s r}$, and for the circumference at point $G$ to $40 \%\left(0.4, \ldots, P_{s r}\right)$.

Similar pressure values were adopted for the arm, that is, $100 \%$ $P_{s r}$ for the wrist circumference, $70 \%$ for the maximum forearm circumference, and $40 \%$ of the $P_{s r}$ value for the arm. Changes in the unit pressure along the length of the leg and arm are shown in Figure 4. After adopting pressure reduction factors $k$, $k_{\max }=1$, the developed algorithm also allows calculating free circumferences of the knitted fabric for therapies requiring a constant value of unit pressure along the covered body part.

In the second part of the algorithm, the free dimensions of the compression knitted fabric are determined. This part of the algorithm is consistent with the calculation procedure presented by Kowalski et al. [22, 23]. The input parameters for this part of the algorithm are body circumferences $G_{1}$, distance between the circumferences and the base $Y_{i}$, and intended values of unit pressure $P_{i}$, determined as the quadratic function

$P_{i}(Y)=A Y_{i}^{2}+B Y_{i}+P_{s r}$

Regression coefficients of the relationship between force and relative elongation of the knitted fabric are $a_{1}, b_{1}$, and $c_{1}$

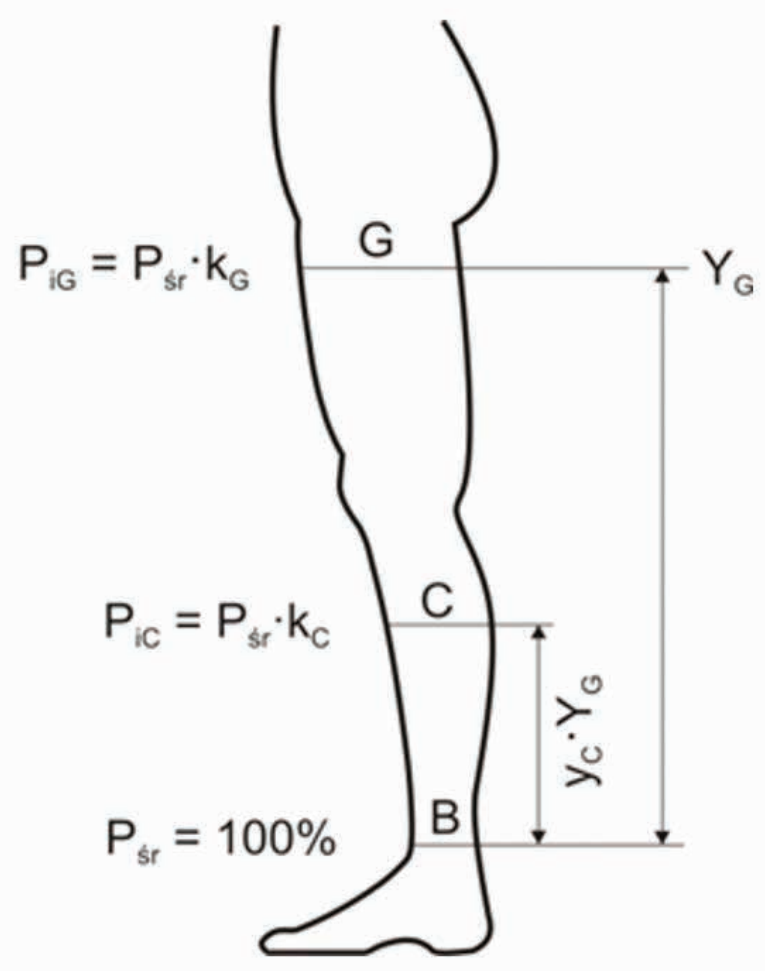

Figure 3. Illustrative model of a leg with characteristic dimensions. accuracy factor of the elongation calculations $\Delta \varepsilon$, and maximum fabric elongation $\varepsilon_{\text {max }}$. The coefficients $\varepsilon_{L}$. and $\varepsilon_{R}$. stand for the range within which we search for the relative elonation value $\varepsilon$. At the beginning this range is $\left\langle 0, \varepsilon_{\max }>\left(\varepsilon_{\max }\right.\right.$ can be equal to 1 or more) and should correspond to the relative useful elongation of the knitted fabric. In the subsequent steps of the calculations bv bisection method, we narrow the range by changing $\varepsilon_{\mathrm{L}}$ or $\varepsilon_{\mathrm{R}}$. As we search for $\varepsilon$ with accuracy to a specified delta, we divide this range until its size is smaller than the delta. Finally, we choose the value of the relative elongation $\varepsilon$ in the middle of the range. In the first part of the algorithm, the values of circumferential forces $F_{i}$ are determined from Laplace's law for the subsequent $G_{i}$ circumferences, and on their basis with the use of fabric characteristic $F=f(\varepsilon)$ the values of relative elongations $\varepsilon$ are determined. Knowing the values of the relative elongations makes it possible to determine the values of fabric circumferences $G_{0 i}$ in the relaxed state. The next step in the calculations is to determine the coordinates of the free dimensions of the model cross sections, which together with the position coordinates of the subsequent circumferences allows to draw the pattern. The coordinates of the template points in the cutter format $Y_{i}, G_{0 i}^{\prime}$ and $Y i, G_{0 i}^{\prime \prime}$ with the program of its control allow automatic template cut, including stitching stocks.

\section{Measuring body parts using 3D scanning techniques}

For measurements of the body part ( $G_{i}$ circumferences) and their position along the body $\left(Y_{i}\right)$, a spatial structured light scanner was used (Figure 5) [23].

The measuring head of the scanner rotates around the scanned object. The scanner configuration is as follows:

- Two 1.3 MPix monochrome cameras;

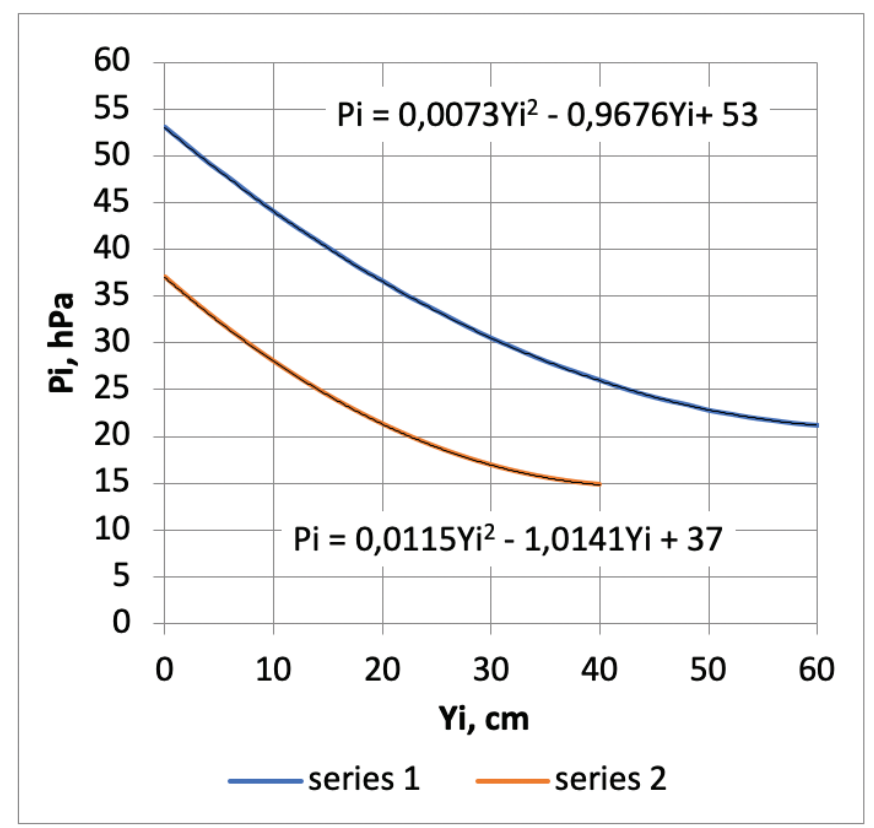

Figure 4. Changes in unit pressure along the leg for class III (series 1) and the hand for class II (series 2). 


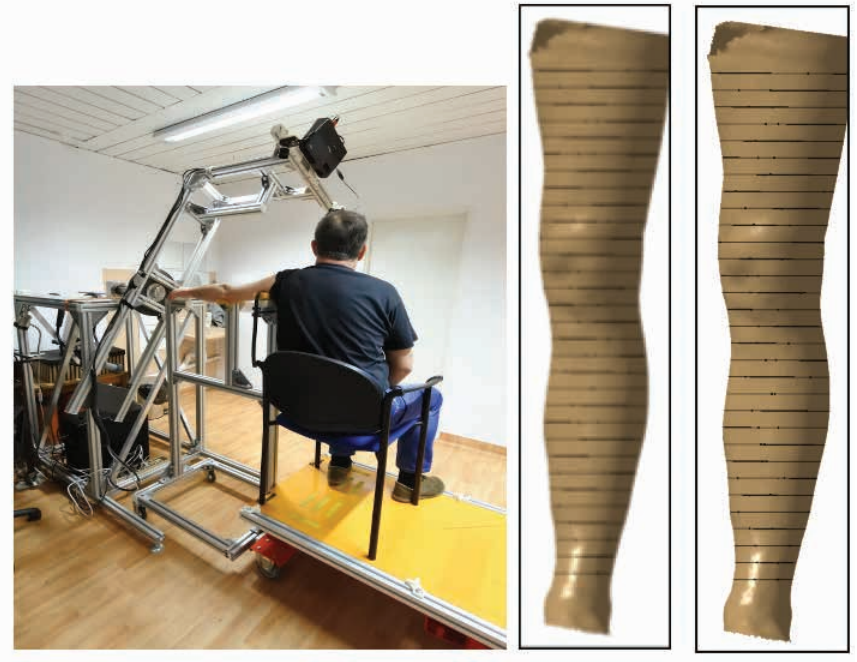

Figure 5. 3D scanner with special equipment for measuring limbs [24].

- $\quad 1,280 \times 1,024$ DLP projector;

- FlexScan3D software version 3.1.

The assessment of the scanning accuracy was based on the VDI/VDE 2634 standard, part 2 "Optical 3D measuring systems - Optical systems based on area scanning." Scans of the leg circumferences were made at every $2 \mathrm{~cm}$ along the length of the leg, starting from the line above the ankle.

\section{Research material}

Sample products in the form of a leg sleeve and arm sleeve were made of knitted fabric with elastomeric threads, whose construction description and basic parameters are presented

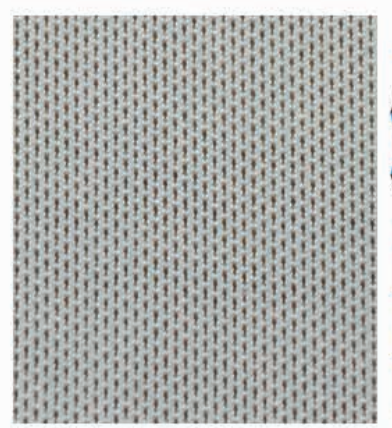

(A)

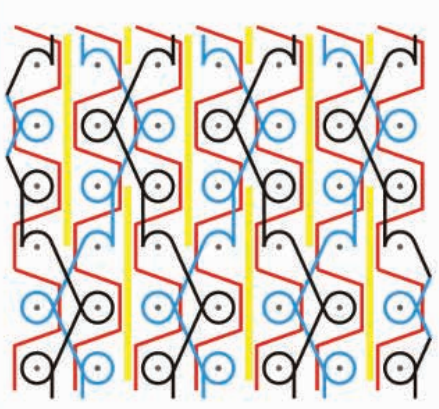

(B)
Figure 6. (A) View of the face of a warp-knitted fabric with elastomeric yarns as the weft. (B) Schematic record of the stitch of a warp-knitted fabric with elastomeric yarns as the weft.

\begin{tabular}{|c|c|}
\hline Fabric properties: & Threads: \\
\hline Wale density $\mathrm{Pk}=120 / 10 \mathrm{~cm}$ & polyamide $78 \mathrm{dtex}$ \\
\hline Course density $\mathrm{Pr}=740 / 10 \mathrm{~cm}$ & $\begin{array}{c}\text { polyurethane weft } \\
480 \mathrm{dtex}\end{array}$ \\
\hline Surface density $\mathrm{M}=234 \mathrm{~g} / \mathrm{m}^{2}$ & \\
\hline
\end{tabular}

in Figures $6 \mathrm{~A}$ and $6 \mathrm{~B}$, and its relationship characteristics of strength and elongation are shown in Figure 7.

The mechanical characteristics of the knitted fabric, namely, the relationship between strength and relative elongation in relation to the width of the knitted fabric strip $s=1 \mathrm{~cm}$, are described as $F=593,1 \varepsilon^{3}-848,1 \varepsilon^{2}+725,7 \varepsilon, R^{2}=0.996$, whose detailed method of determination and justification based on the rheological model are presented by Kowalski et al. [18]. The method of determining the mechanical characteristics of knitted fabric for the purpose of designing compression products is based on the same principles of determining the force $F$ in function of the relative elongation of the fabric $e$ in terms of the number of stretching and annealing cycles and for various stretching subranges, as in the method of testing compression products [25].

This eliminates the causes of errors in the design of compression products with the intended unit pressure value, as it takes into account the differences in the relationship between the values of $F$ and $\varepsilon$, depending on the extent of stretching and rheological properties of the tested compression knitted fabrics.

\section{Results}

\subsection{Designing a template for a leg sleeve with compression class III and arm sleeve with compression class II}

The design procedure for compression products with the intended graded value of unit pressure along the length of the product was carried out on the basis of the developed generalized algorithm for determining the template coordinates and model-experimental research. As mentioned above, the project concerns the development of a male leg sleeve and arm sleeve for a woman, both used in the treatment of lymphoedema. The treatment of lymphoedema with appropriately selected

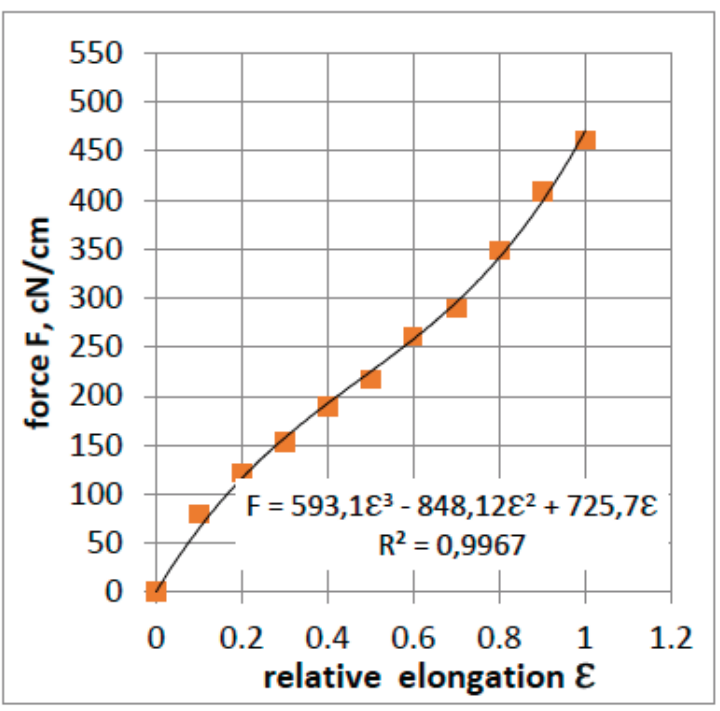

Figure 7. Values of strength as a function of relative elongation in six hysteresis loops for various ranges of knitwear stretching. 


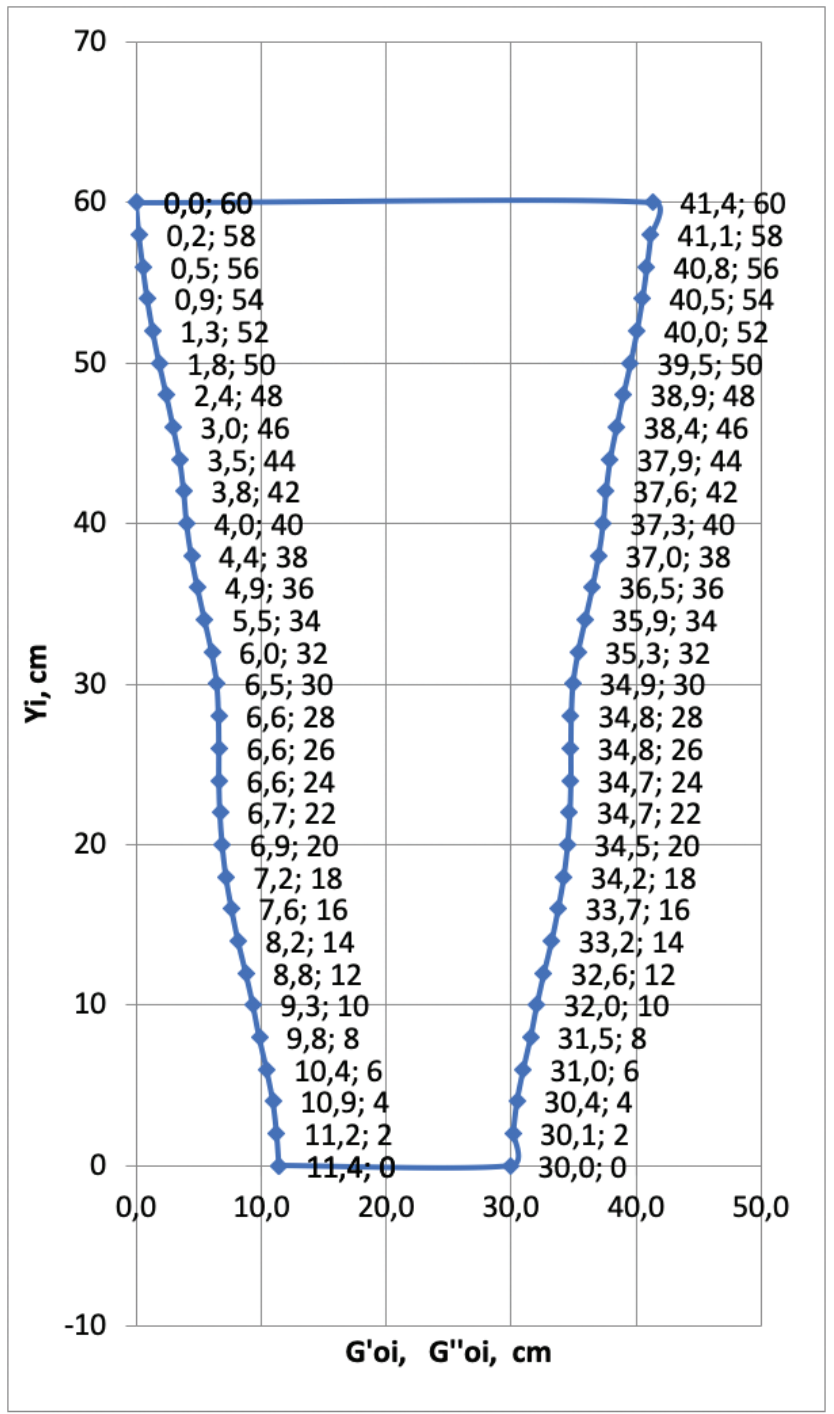

Figure 8. Leg sleeve template for lympho,edema treatment together with template coordinates $\mathrm{Yi}, G_{0 i}^{\prime}$, and $G_{0 i}(\mathrm{~cm})$.
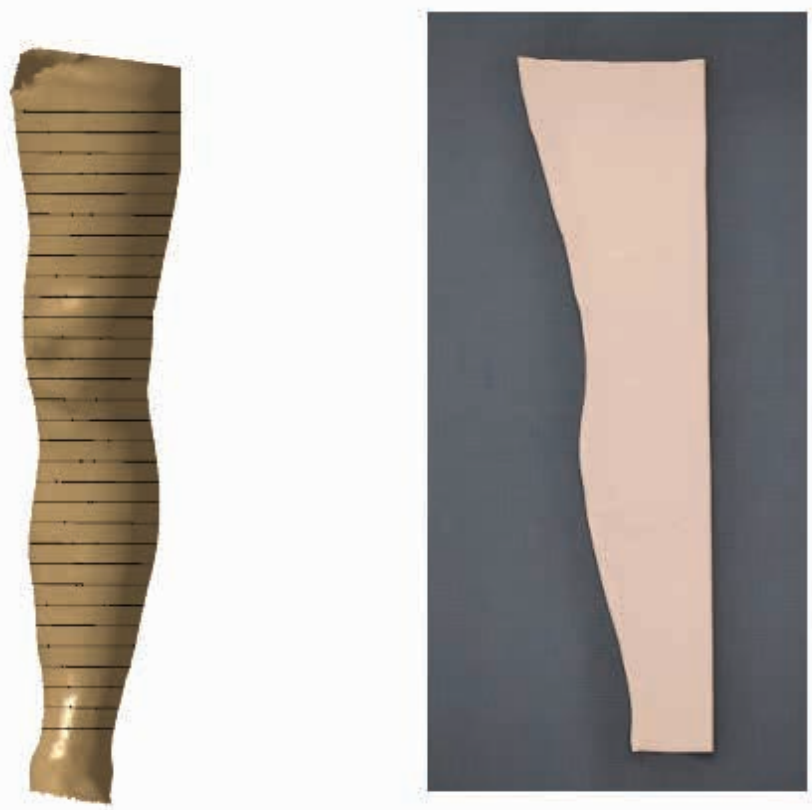

Figure 10. Leg sleeve used in lymphoedema treatment.

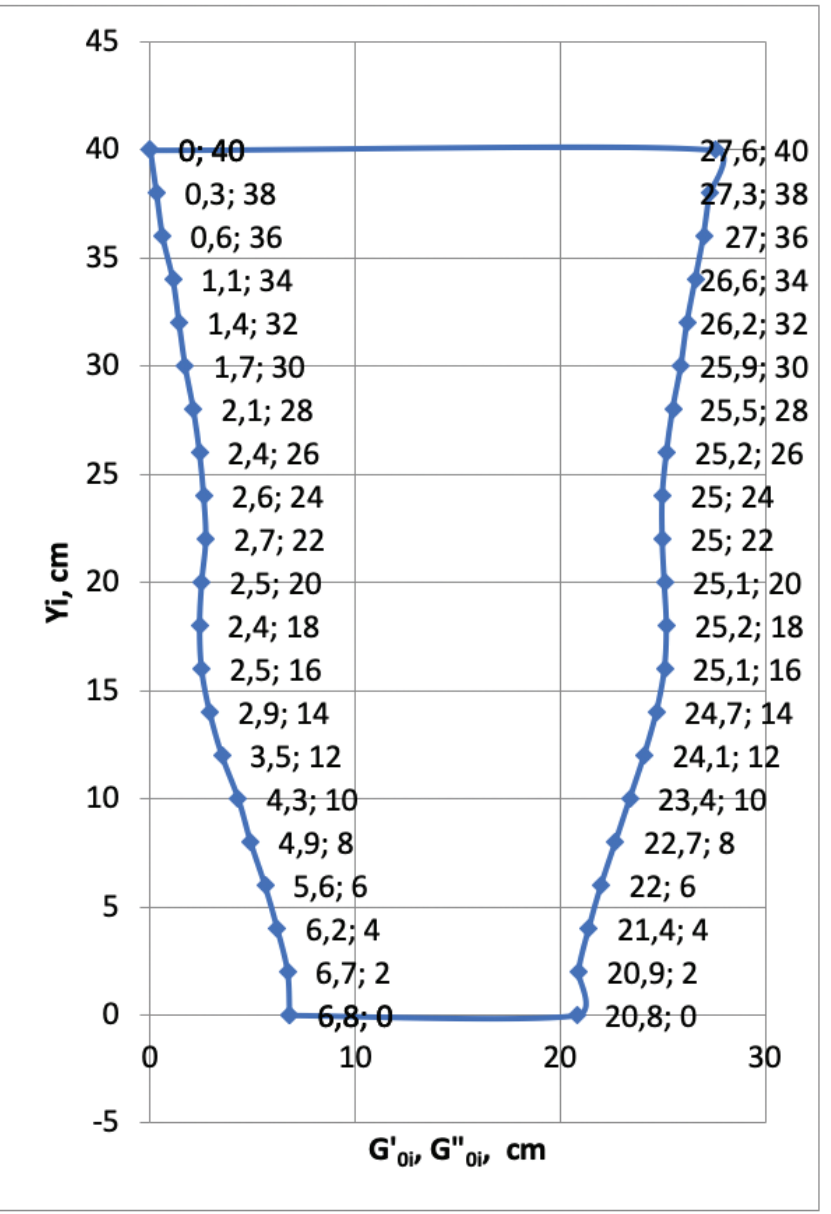

Figure 9. Arm sleeve template for lymphoedema treatment together with template coordinates $\mathrm{Yi}, G_{0 i}^{\prime}$, and $G_{0 i}^{\prime \prime}(\mathrm{cm})$.

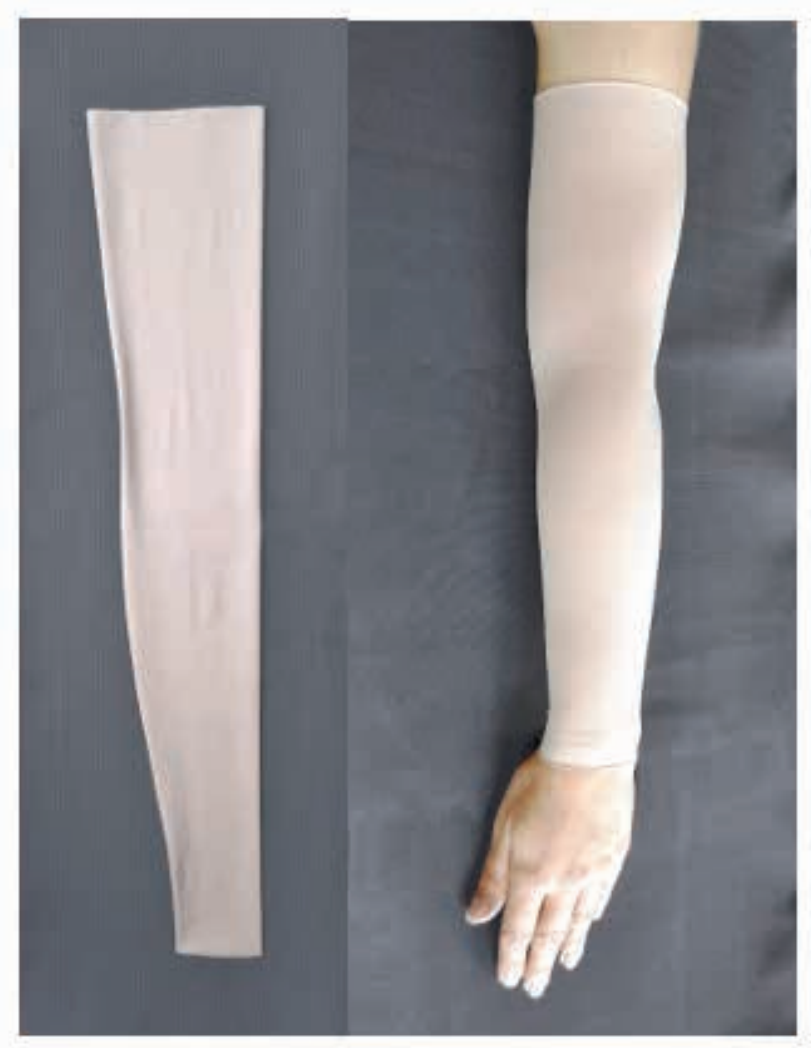

Figure 11. Arm sleeve used in lymphoedema treatment. 
Table 1. The results of calculating the pressure value and template profile for , the leg sleeve in the form of the coordinates of the points $Y_{i}$, $G_{0 i}^{\prime}, G_{0 i}^{\prime \prime}, \mathrm{G}_{0 i}$

\begin{tabular}{|c|c|c|c|c|c|}
\hline Ls & $\mathbf{s}$ & $a_{1}$ & $a_{2}$ & $a_{3}$ & \\
\hline $0.6 \mathrm{~cm}$ & $1 \mathrm{~cm}$ & 593.1 & -848.1 & 725.7 & \\
\hline$G_{i}(\mathrm{~cm})$ & $Y_{i}(\mathrm{~cm})$ & $P_{i}(\mathrm{hPa})$ & $\begin{array}{c}G_{0 i}^{\prime} \\
(\mathrm{cm})\end{array}$ & $\begin{array}{c}G_{0 i}^{\prime \prime} \\
(\mathrm{cm})\end{array}$ & $\mathbf{G}_{0 \mathrm{i}}(\mathrm{cm})$ \\
\hline 57.1 & 60 & 21.2 & 41.4 & 0.0 & 41.4 \\
\hline 56.4 & 58 & 21.4 & 41.1 & 0.2 & 40.9 \\
\hline 55.4 & 56 & 21.7 & 40.8 & 0.5 & 40.3 \\
\hline 54.3 & 54 & 22.0 & 40.5 & 0.9 & 39.6 \\
\hline 52.9 & 52 & 22.4 & 40.0 & 1.3 & 38.7 \\
\hline 51.2 & 50 & 22.8 & 39.5 & 1.8 & 37.7 \\
\hline 49.3 & 48 & 23.4 & 38.9 & 2.4 & 36.5 \\
\hline 47.6 & 46 & 23.9 & 38.4 & 3.0 & 35.4 \\
\hline 46.1 & 44 & 24.5 & 37.9 & 3.5 & 34.4 \\
\hline 45.4 & 42 & 25.2 & 37.6 & 3.8 & 33.8 \\
\hline 45.2 & 40 & 26.0 & 37.3 & 4.0 & 33.3 \\
\hline 44.4 & 38 & 26.8 & 37.0 & 4.4 & 32.6 \\
\hline 43 & 36 & 27.6 & 36.5 & 4.9 & 31.6 \\
\hline 41.3 & 34 & 28.5 & 35.9 & 5.5 & 30.4 \\
\hline 39.6 & 32 & 29.5 & 35.3 & 6.0 & 29.3 \\
\hline 38.6 & 30 & 30.5 & 34.9 & 6.5 & 28.5 \\
\hline 38.9 & 28 & 31.6 & 34.8 & 6.6 & 28.2 \\
\hline 39.8 & 26 & 32.8 & 34.8 & 6.6 & 28.1 \\
\hline 41 & 24 & 34.0 & 34.7 & 6.6 & 28.1 \\
\hline 41.9 & 22 & 35.2 & 34.7 & 6.7 & 28.0 \\
\hline 42.2 & 20 & 36.6 & 34.5 & 6.9 & 27.6 \\
\hline 41.8 & 18 & 37.9 & 34.2 & 7.2 & 27.0 \\
\hline 40.5 & 16 & 39.4 & 33.7 & 7.6 & 26.1 \\
\hline 38.7 & 14 & 40.9 & 33.2 & 8.2 & 25.1 \\
\hline 36.3 & 12 & 42.4 & 32.6 & 8.8 & 23.8 \\
\hline 34.1 & 10 & 44.0 & 32.0 & 9.3 & 22.7 \\
\hline 32.3 & 8 & 45.7 & 31.5 & 9.8 & 21.7 \\
\hline 30 & 6 & 47.5 & 31.0 & 10.4 & 20.5 \\
\hline 28.1 & 4 & 49.2 & 30.4 & 10.9 & 19.5 \\
\hline 27.3 & 2 & 51.1 & 30.1 & 11.2 & 18.9 \\
\hline 27.1 & 0 & 53.0 & 30.0 & 11.4 & 18.5 \\
\hline
\end{tabular}

compression garments should, according to the literature data [28], adhere to the following principles:

1. Compression garments should be custom-made based on measurements of the patient's body in the final stage of the first therapeutic phase, when the limb is free from swelling or the edema is stable;

2. While waiting for the device, the patient must continue to use multilayer bandaging;

3. The greater the lymphatic insufficiency, the stronger the pressure that should be applied;

4. For the upper limbs, products in compression class I or II are usually sufficient; 
5. On the lower limbs, compression classes III and IV are used most often;

6. Knitted fabric from which the garments are made should have relatively high elongation stiffness;

7. Due to skin protection, the material should not cause indentations or rolling;

8. Garments should be worn only during the day;

9. The patient should order two products to allow their daily, uninterrupted use.

The determined values of the coordinates of the $G_{0 i}^{\prime}$ and $G_{0 i}^{\prime \prime}$ templates together with the coordinates of their position along the length of the limb are presented in Tables 1 and 2 . The free dimensions of the circumferences also include stitch reserves. The drawn templates are illustrated in Figures 8 and 9, and the views of the designed and manufactured products are shown in Figures 10 and 11.

\section{Discussion}

\subsection{Experimental verification}

Based on the calculation data presented in Table 1, the values of the knitted fabric's relative elongation were determined for three measuring points $B, C$, and $G$ (Figure 3 ), in accordance with Eq. (3). For the determined values of relative elongation $\varepsilon$, the force $F$ in the knitted fabric was measured (Figure 12). For this purpose, samples of knitted fabric from which the stockings are made were taken - for points $B, C$, and $G$, according to the standard [25]. Then the samples were subjected to the process of stressing and annealing to the determined values of relative

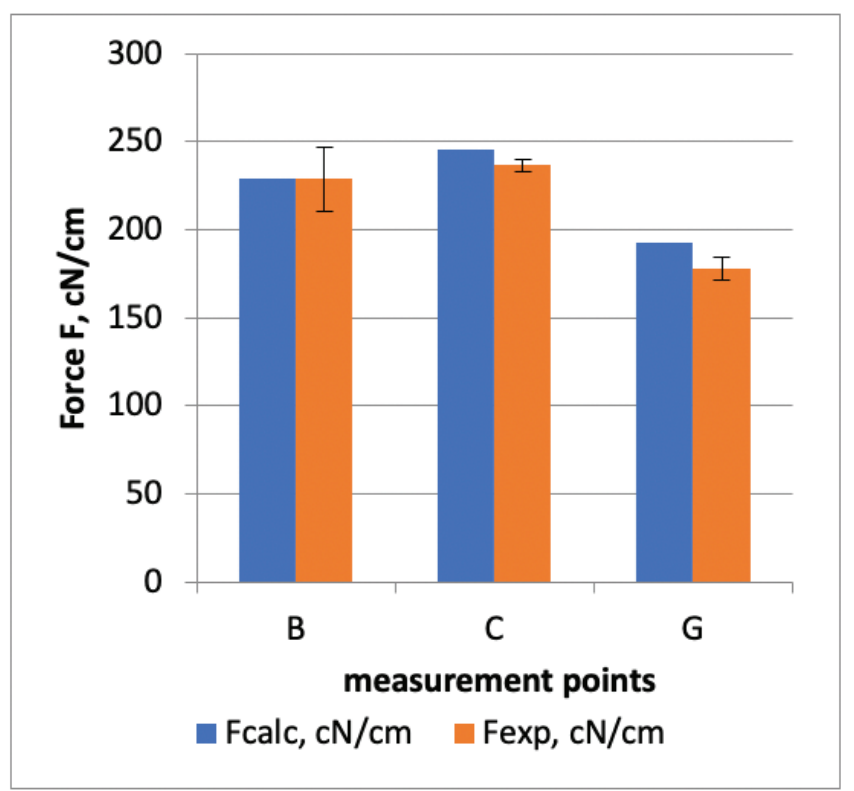

Figure 12. Test results for forces in the knitted fabric for three measuring points $B, C$, and $G$ for leg (Figure 3 ). $F_{\text {calc }}$ - intended values of peripheral force, $F_{\text {exp }}$ - measured values of force. elongations $\varepsilon$. For each value of relative elongation, tests were carried out for five $50-\mathrm{mm}$ wide samples in the form of a 100- $\mathrm{mm}$ free loop between the clamps of the tensile machine. The tests were carried out at a speed of $200 \mathrm{~mm} / \mathrm{min}$ on the Instron tensile machine, with the use of needles stabilizing the width of the fabric. The value of force $F$ was taken from six hysteresis loops after the end of the stressing phase [18]. According to Laplace's law (1), the value of unit pressure $P$ in $\mathrm{hPa}$ was calculated for three values of body circumferences at points $B, C$, and $G$ (Figure 13).

Experimental verification of the unit pressure for selected body circumferences confirmed the correctness of the adopted procedure of designing and manufacturing products with the graded unit pressure. The maximum percentage difference between the intended and experimentally determined values was $7.5 \%$ for the circumference at point $\mathrm{G}$ (thigh circumference). The differences can be attributed to the sample manufacturing tolerance, which is $\pm 0.2 \mathrm{~cm}$ (manual cut and joining by seam) and the difference between the values of the regression function of the mechanical characteristic of the compression knitted fabric in the form of a relationship of strength and relative elongation (Figure 7), and the values determined for analyzed points determined by the value of relative elongation.

It is widely known that there are difficulties in putting on compression garments in higher compression classes (II-IV) due to the high values of circumferential forces. This problem also appears even for the class I compression for large circumference values, for example, the body trunk in the case of treatment of post-burn scars. In such cases, one of the ways of solving the problem is by putting on two products, each designed with a two-times smaller value of the unit pressure compared with the intended value $[8,9]$.

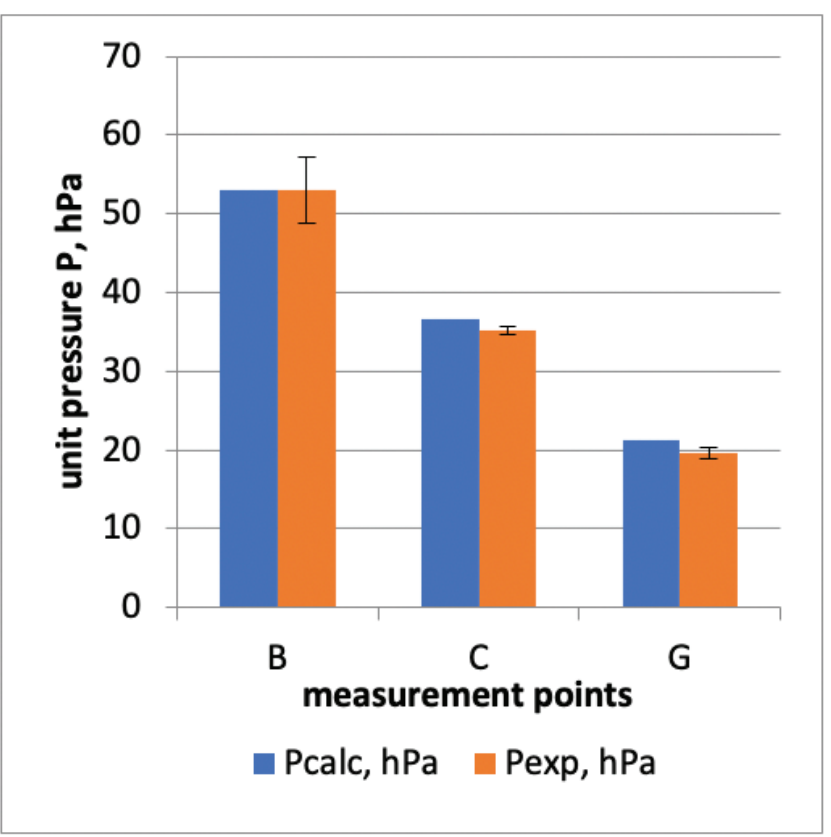

Figure 13. Unit pressure values for three measuring points $B, C$, and $G$ for the leg (Figure 3). $P_{\text {calc }}$ - intended pressure value, $P_{\text {exp }}$-determined pressure value based on Laplace's law and measured force values. 


\section{Conclusions}

1. The presented procedure of designing a compression garment with a graded pressure using a computer program and $3 \mathrm{D}$ body scanning as well as the procedures for determining the mechanical characteristics of knitted fabric in the form of the function of force $F$ and relative elongation of the knitted fabric $\varepsilon F=f(\varepsilon)$ improve and eliminate some errors in the design of compression garments.

2. Experimental verification of unit pressures for selected body circumferences confirmed the correctness of the adopted design procedure. The existing differences between the intended values of the unit pressure and the values from the measurement should be attributed to the band tolerance of $\pm 0.2 \mathrm{~cm}$ (manual cut and joining by seams) and the difference between the values of the strength of the regression function of the mechanical characteristics of the compression knit in the form of a relationship of strength and relative elongation (Figure 7) and the values determined for the analyzed points determined by the value of relative elongation.

3. An important general condition in the design procedure for compression garments with the intended unit pressure is the compliance of the compression products test method [25], with the method of determining the mechanical characteristics of knitted fabric in the form of a function of strength and relative elongation [18].

\section{References}

[1] Maklewska, E., Nawrocki, A., Ledwoń, J., Kowalski, K. (2006). Modelling and designing of knitted products used in compressive therapy. Fibres \& Textiles in Eastern Europe, 14(5), 111-113.

[2] Abbas, M. S., Mansour, R., Zeynab, S. (2008). The analytical study of garment pressure on the human body using finite elements. Fibres \& Textiles in Eastern Europe, 3(68), 69-73.

[3] Ališauskiené, D., Mikučionienè, D. (2012). Influence of the rigid element area on the compression properties of knitted orthopaedic supports. Fibres \& Textiles in Eastern Europe, 20, 6A(95), 103-107.

[4] Kowalski, K., Mielicka, E., Kowalski, T. M. (2012). Modeling and design of compression products of the intended unit pressure for the circuits of the body with a variable radius of curvature. Fibres \& Textiles in Eastern Europe, 20, 6A(95), 98-102.

[5] Kirstein, T., Krzywinski, S. (1994). Fit optimisation for closefitting garments with regard to material properties. Institute for Textile and Clothing Technology (Dresden University of Technology), 6(4), 17-27.

[6] Ng, S. F. F., Hui, C. L. P. (1999). Effect of hem edges on the interface pressure of pressure garments. International Journal of Clothing Science and Technology, 11(5), 251261.

[7] Ng, S. F., Hui, C. L. P. (2001). Pressure model of elastic fabric for producing pressure garments. Textile Research Journal, 71(3), 275-279.
[8] Macityre, L., Baird, M., Weedall, P. (2000). Elastic fabrics for use in pressure garments - comfort properties. World Textile Congress (Heriot-Watt University UK), 74-81.

[9] Macintyre, L., Margot, B. (2006). Pressure garments for use in the treatment of hypertrophic scars-a review of the problems associated with their use. Burns, 32, 10-15.

[10] Salleh, M. N. B., Acar, M., Burns, N. D. (1997). Customised pressure garment development by using $3 D$ scanned body image. Research Journal of Textile and Apparel, 15(4).

[11] Whitestone, J. J., Richard, R. L., Slemker, T. C., AuseEllias, K. L., Miller, S. F. (1995). Fabrication of totalcontact burn masks by use of human body topography and computer-aided. Journal of Burn Care \& Rehabilitation, 16(5), 543-547.

[12] Hu, Z.-H., Ding, Y.-S., Zhang, W.-B., Yan, Q. (2008). An interactive co-evolutionary CAD system for garment pattern design. Computer-Aided Design, 40(2008) 10941104.

[13] Yang, Y. C., Zou, Z. Y., Li, Z., Ji, X. F., Chen, M. Z. (2011). Development of a prototype pattern based on the $3 D$ surface flattening method for MTM garment production. Fibres \& Textiles in Eastern Europe, 19, 5(88), 107-111

[14]. Yang, Y. C., Zhang, W. Y. (2007). Prototype garment pattern fattening based on individual $3 D$ virtual dummy. International Journal of Clothing Science and Technology, 19(5), 334-348.

[15]. Petrak, S., Mahnic, M., Ujevic, D. (2012). Study of the computer-based adjustment of a $3 D$ body model based on anthropometric data obtained by $3 D$ laser scanner. In: D'Apuzzo, N. (Ed.). Proceedings of the 3rd International Conference on 3D Body Scanning Technologies, Lugano, Switzerland, 2012, pp. 115-126.

[16] Derejczyk, K., Siemiński, P. (2016). Analiza dokładności metod optycznego skanowania 3D. doi: 10.17814/ Mechanik. 2016.4.41

[17] Ilska, A., Kowalski, K., Kłonowska, M., Kuzański, W., Kowalski, T. M., et al. (2017). Using a 3D body scanner in designing compression products supporting external treatment. Fibres \& Textiles in Eastern Europe, 25, 5(125), 107-112.

[18] Kowalski, K., Kłonowska, M., Ilska, A., Sujka, W., Tyczyńska, M. (2018). Methods of evaluating knitted fabrics with elastomeric threads in the design process of compression products. Fibres \& Textiles in Eastern Europe, 26, 3(129), 60-65.

[19] Ilska, A., Kowalski, K., Kłonowska, M., Kowalski, T. M., Sujka, W. (2016). Issues regarding the design of compression products for small body circumferences. Fibres \& Textiles in Eastern Europe, 24, 6(120), 116-120.

[20] Kowalski, K., Kłonowska, M., Ilska, A. (2020). Selecting appropriate longitudinal rigidity of knitted fabric in compression products of standardised size. Fibres \& Textiles in Eastern Europe, 28, 3(141), 44-49.

[21] Ilska, A., Kowalski, K., Kłonowska, M., Kowalski, T. M. (2014). Influence of stress and relaxation characteristics of knitted fabrics on the unit pressure of compression garments supporting external treatment. Fibres and Textiles in Eastern Europe, 22, 4(106).

[22] Kowalski, K., Karbowski, K., Kłonowska, M., Prążyńska, A., Sujka, W., Kowalski, T. M. (2018). Designing seamless compression products supporting the process of external treatment on numerically controlled flat knitting machines. Fibres \& Textiles in Eastern Europe, 26, 4(130), 75-81. 
[23] Kowalski, K., Karbowski, K., Kłonowska, M., Ilska, A., Sujka, W., et al. (2017). Influence of a compression garment on average and local changes in unit pressure. Fibres \& Textiles in Eastern Europe, 25, 6(126), 68-74.

[24] Kowalski, K., Kłonowska, M., Ilska, A. (2020). Selecting appropriate longitudinal rigidity of knitted fabric in compression products of standardised size. Fibres \& Textiles in Eastern Europe, 28, 3(141), 44-49.

[25] CEN/TR 15831:2009 (2009). Method for testing compression in medical hosiery.
[26] RAL-GZ 387/1 Medizinische Kompressiosstruempfe Ausgabe Januar 2008.

[27] RAL-GZ 387/2 Medizinische Kompressiosstruempfe Ausgabe Januar 2008.

[28] Narojczyk, A. (2009). Centrum Flebologii, przedstawiciel BSN-JOBST. Kompresjoterapia w leczeniu obrzęków limfatycznych. 